\title{
Kinerja Algoritma Support Vector Machine dalam Menentukan Kebenaran Informasi Banjir di Twitter
}

\author{
Muhamad Prasetio Dwi Cahyo ${ }^{1}$, Widodo², Bambang P. Adhi ${ }^{3}$ \\ 1,2,3 Pendidikan Teknik Informatika dan Komputer Fakultas Teknik \\ Universitas Negeri Jakarta \\ Email: mprasetiodc@gmail.com ,2widodo@unj.ac.id, 3bambangpadhi@unj.ac.id
}

\begin{abstract}
ABSTRAK
Menurut survei yang dilakukan oleh Asosiasi Penyelenggara Jaringan Internet Indonesia (APJII) mengatakan bahwa sepanjang 2016 sebanyak 132,7 juta orang telah terhubung ke internet. Dalam penggunaan internet seseorang dapat berkomunikasi melalui jejaring sosial. Jejaring sosial adalah sarana untuk bersosialisasi satu sama lain secara online didunia maya (internet). Twitter adalah salah satu dari macam-macam jejaring sosial. Menurut catatan Badan Penanggulangan Bencana Daerah (BPBD) Jakarta terdapat 700 kasus banjir selama periode Januari-Agustus 2016. Pada twitter terdapat user yang memberikan informasi tentang banjir dengan mengirimkan sebuah tweet. Namun penggunaan kata "banjir" tidak semua dimaksudkan untuk memberi informasi mengenai banjir. Ada yang menggunakannya hanya sebagai kata kiasan. Penelitian ini menggunakan algoritma Support Vector Machine untuk mengklasifikasi tweet yang benar memberikan informasi mengenai banjir atau tidak. Algoritma Support Vector Machine adalah suatu algoritma yang memiliki tingkat akurasi yang tinggi. Dalam penelitian ini untuk mengevaluasi tingkat akurasi dari algoritma Support Vector Machine menggunakan Confusion Matrix. Hasilnya adalah tingkat akurasi dari Support Vector

Machine dalam menentukan tweet mengenai informasi banjir sebesar 0,96.
\end{abstract}

Kata Kunci : Twitter, Banjir, Informasi, Support Vector Machine, Confusion Matrix.

\section{PENDAHULUAN}

Teknologi di era globalisasi saat ini sudah berkembang, terutama dalam penggunaan internet. Penggunaan internet di berbagai elemen masyarakat sudah berpengaruh besar terhadap kehidupan sehari-hari. Menurut survei yang dilakukan oleh Asosiasi Penyelenggara Jaringan Internet Indonesia (APJII) yang dimuat oleh www.tekno.kompas.com mengungkap bahwa lebih dari setengah penduduk Indonesia kini telah terhubung ke internet. Survei yang dilakukan sepanjang 2016 itu menemukan bahwa 132,7 juta orang Indonesia telah terhubung ke internet. Adapun total penduduk Indonesia sendiri sebanyak 256,2 juta orang. Dengan menggunakan internet saat ini dapat memudahkan seseorang dalam berkomunikasi satu sama lain, salah satunya melalui jejaring sosial.
Jejaring sosial adalah sarana untuk bersosialisasi satu sama lain secara online didunia maya (internet). Twitter adalah salah satu dari macam-macam jejaring sosial. Twitter adalah layanan jejaring sosial yang memungkinkan penggunanya untuk mengirim pesan, yang dikenal dengan sebutan kicauan (tweet). Dengan jejaring sosial Twitter penggunanya dapat dengan mudah berkomunikasi atau memberi informasi baru terkait keadaan lingkungan sekitarnya. Informasi yang sering kita peroleh dari jejaring sosial twitter mengenai fenomena alam seperti banjir.

Seperti yang diketahui fenomena banjir sering terjadi di daerah DKI Jakarta. Menurut catatan Badan Penanggulangan Bencana Daerah (BPBD) Jakarta terdapat 700 kasus banjir selama periode Januari-Agustus 2016. Banyak pengguna twitter memberikan 
informasi mengenai banjir di daerah lingkungannya dengan cara membuat tweet.

Namun tidak semua tweet yang berisi kata "banjir" adalah informasi mengenai lokasi yang sedang terkena banjir. Sebagian ada pengguna jejaring sosial twitter lainnya yang menggunakan kata "banjir" tetapi tidak memberikan informasi mengenai banjir namun penggunaanya hanya sebagai kiasan.

Atas dasar tersebut, maka peneliti merasa perlu untuk mengklasifikasi tweet yang berisi informasi tentang banjir yang akurat, agar memudahkan masyarakat untuk dapat informasi yang mereka inginkan. Dalam mengklasifikasi text terdapat beberapa metode algortima, seperti Support Vector Machine, Naive Bayes, Decision Tree, etc. Untuk mengklasifikasi tweet yang berisikan informasi mengenai banjir, peneliti menggunakan algortima Support Vector Machine. Support Vector Machine memiliki kelebihan yaitu mampu mengidentifikasikan hyperplane terpisah yang memaksimalkan margin antara dua kelas yang berbeda (Chou et al., 2014). Pertimbangan peneliti menggunakan algoritma Support Vector Machine karena algortima tersebut memiliki tingkat akurasi yang tinggi seperti dalam penelitian yang dilakukan oleh Achamd Nurhadi (2015) yang menggunakan algortima tersebut dalam mengklasifikasi konten berita digital bahasa Indonesia, menghasilkan nilai akurasi sebesar $95.42 \%$. Jadi penelitian ini difokuskan untuk implementasi algoritma Support Vector Machine dalam pengklasifikasi tweet mengenai banjir.

\section{DASAR TEORI \\ 2.1. Kajian Teoritik \\ 2.1.1. Banjir}

Banjir adalah fenomena alam yang terjadi di kawasan yang banyak dialiri oleh aliran sungai. Sedangkan secara sederhana, banjir didefinisikan sebagai hadirnya air suatu kawasan luas sehingga menutupi permukaan bumi kawasan tersebut. Berdasarkan SK SNI M-18-1989-F (1989) dalam Suparta 2004, bahwa banjir adalah aliran air yang relatif tinggi, dan tidak tertampung oleh alur sungai atau saluran.

\subsubsection{Text Mining}

Menurut Han \& Kamber (2006) yang diacu dalam Kestrilia Rega Prilianti \& Hendra Wijaya (2014: 1) text mining adalah satu langkah dari analisis teks yang dilakukan secara otomatis oleh komputer untuk menggali informasi yang berkualitas dari suatu rangkaian teks yang terangkum dalam sebuah dokumen.

\subsubsection{Support Vector Machine}

Menurut (Nello Christianini dan John S. Taylor, 2000) yang diacu dalam Dwi Astuti (2007:2) Support Vector Machine (SVM) adalah sistem pembelajaran yang pengklasifikasiannya menggunakan ruang hipotesis berupa fungsi-fungsi linear dalam sebuah ruang fitur (feature space) berdimensi tinggi, dilatih dengan algoritma pembelajaran yang didasarkan pada teori optimasi dengan mengimplementasikan learning bias yang berasal dari teori pembelajaran statistik.

Langkah awal suatu algoritma SVM adalah pendefinisian persamaan suatu hyperplane pemisah yang dituliskan dengan:

$$
\mathrm{W} . \mathrm{X}+\mathrm{b}=0
$$

$\mathrm{W}$ adalah suatu bobot vektor, yaitu $\mathrm{W}=$ $\{\mathrm{W} 1, \mathrm{~W} 2, \ldots, \mathrm{Wn}\} ; \mathrm{n}$ adalah jumlah atribut dan $b$ merupakan suatu skalar yang disebut dengan bias. Jika berdasarkan pada atribut A1, A2 dengan permisalan tupel pelatihan $\mathrm{X}$ $=(\mathrm{x} 1, \mathrm{x} 2), \mathrm{x} 1$ dan $\mathrm{x} 2$ merupakan nilai dari atribut A1 dan A2, dan jika b dianggap sebagai suatu bobot tambahan w0, maka persamaan suatu hyperplane pemisah dapat ditulis ulang sebagai berikut:

$$
\mathrm{w}_{0}+\mathrm{w}_{1} \mathrm{w}_{1}+\mathrm{w}_{2} \mathrm{w}_{2}=0
$$

Setelah persamaan dapat didefinisikan, nilai $\mathrm{x} 1$ dan $\mathrm{x} 2$ dapat dimasukkan ke dalam persamaan untuk mencari bobot $\mathrm{w} 1$, w2, dan w0 atau b.

SVM menemukan hyperplane pemisah maksimum, yaitu hyperplane yang mempunyai jarak maksimum antara tupel pelatihan terdekat. Support vector ditunjukkan dengan batasan tebal pada titik tupel. Dengan demikian, setiap titik yang terletak di atas hyperplane pemisah memenuhi rumus:

$$
\mathrm{w}_{0}+\mathrm{w}_{1} \mathrm{w}_{1}+\mathrm{w}_{2} \mathrm{w}_{2}>0
$$

Sedangkan, titik yang terletak di bawah hyperplane pemisah memenuhi rumus:

$$
\mathrm{w}_{0}+\mathrm{w}_{1} \mathrm{w}_{1}+\mathrm{w}_{2} \mathrm{w}_{2}<0
$$

Melihat dua kondisi di atas, maka didapatkan dua persamaan hyperplane yaitu:

$$
\begin{gathered}
\mathrm{H}_{1}: \mathrm{w}_{0}+\mathrm{w}_{1} \mathrm{w}_{1}+\mathrm{w}_{2} \mathrm{w}_{2} \geq 1 \\
\text { untuk } \mathrm{y}_{\mathrm{i}}=+1 \\
\mathrm{H}_{2}: \mathrm{w}_{0}+\mathrm{w}_{1} \mathrm{w}_{1}+\mathrm{w}_{2} \mathrm{w}_{2} \leq-1
\end{gathered}
$$




$$
\text { untuk } \mathrm{y}_{\mathrm{i}}=-1
$$

Perumusan model SVM menggunakan trik matematika yaitu formula Lagrangian. Berdasarkan Lagrangian formulation, Maksimum Margin Hyperplane (MMH) dapat ditulis ulang sebagai suatu batas keputusan (decision boundary) yaitu:

$$
\mathrm{d}\left(\mathrm{X}^{\mathrm{T}}\right)=\sum_{\mathrm{i}=1}^{\mathrm{l}} \mathrm{y}_{\mathrm{i}} \mathrm{a}_{\mathrm{i}} \mathrm{X}_{\mathrm{i}} \mathrm{X}^{\mathrm{T}}+\mathrm{b}_{0}
$$

yi adalah label kelas dari support vector Xi. XT merupakan suatu tupel test. $\alpha \mathrm{i}$ dan b0 adalah parameter numerik yang ditentukan secara otomatis oleh optimalisasi algoritma SVM dan 1 adalah jumlah vector support.

\subsubsection{Informasi}

Menurut (Tata Sutabri 2005:23) diacu dalam Slamet Pebrianto (2010:2) Informasi adalah data yang telah diklasifikasikan atau diolah atau diinterprestasi untuk digunakan dalam proses pengambilan keputusan.

\subsubsection{Twitter}

Menurut Domikus Juju \& MataMaya Studio (2009: 2-3) di acu dalam Dika Putri Utama, dkk (2015: 5) definisi dari twitter adalah sebuah web dan layanan mikroblog yang bisa digunakan untuk melakukan pembaharuan (update) berupa sebuah teks panjang maksimum sebanyak 140 karakter, pembaharuan (update) di twitter dikenal sebagai tweets.

\subsubsection{Confusion Matrix}

Metode ini menggunakan tabel matriks seperti pada Tabel 1 jika data set hanya terdiri dari dua kelas, kelas yang satu dianggap sebagai positif dan yang lainnya negatif (Bramer, 2007). Confusion Matrix adalah tools yang digunakan untuk evaluasi model klasifikasi untuk memperkirakan objek yang benar atau salah.

Tabel 2.1. Model Confusion Matrix (Bramer, 2007)

\begin{tabular}{|l|c|c|}
\hline Klasifikasi & \multicolumn{2}{|c|}{ Diklasifikasikan sebagai } \\
\cline { 2 - 3 } yang benar & + & - \\
\hline \multirow{3}{*}{+} & $\mathrm{TP}$ & $\mathrm{FN}$ \\
& true & false \\
& positives & negatives \\
\hline \multirow{2}{*}{-} & $\mathrm{FP}$ & $\mathrm{TN}$ \\
& false & true \\
& positives & negatives \\
\hline
\end{tabular}

True positives adalah jumlah record positif yang diklasifikasikan sebagai positif, false positives adalah jumlah record negatif yang diklasifikasikan sebagai positif, false negatives adalah jumlah record positif yang diklasifikasikan sebagai negatif, true negatives adalah jumlah record negatif yang diklasifikasikan sebagai negative. Evaluasi dan validasi hasil dihitung menggunakan rumus akurasi, precision, recall dan $f$ measure berikut ini:

- Akurasi

Perhitungan akurasi dilakukan dengan cara membagi jumlah data yang diklasifikasi secara benar dengan total sample data testing yang diuji.

$$
\text { Accuracy }=\frac{\mathrm{TP}+\mathrm{TN}}{\mathrm{TP}+\mathrm{TN}+\mathrm{FP}+\mathrm{FN}}
$$

- $\quad$ Precision

Menghitung nilai precision dengan cara membagi jumlah data benar yang bernilai positif (True Positive) dibagi dengan jumlah data benar yang bernilai positif (True Positive) dan data salah yang bernilai positif (False Negative).

- Recall

$$
\text { Precision }=\frac{\mathrm{TP}}{\mathrm{TP}+\mathrm{FP}}
$$

Sedangkan recall dihitung dengan cara membagi data benar yang bernilai positif (True Positive) dengan hasil penjumlahan dari data benar yang bernilai positif (True Positive) dan data salah yang bernilai negatif (False Negative).

\section{- F-Measure}

$$
\text { Recall }=\frac{\mathrm{TP}}{\mathrm{TP}+\mathrm{FN}}
$$

Nilai F-Measure didapat dari perhitungan pembagian hasil dari perkalian precision dan recall dengan hasil penjumlahan precision dan recall, kemudian dikalikan dua.

$$
F-\text { Measure }=2 * \frac{\text { precision } * \text { recall }}{\text { precision }+ \text { recall }}
$$

\subsection{Prosedur}

Berdasarkan identifikasi masalah yang telah dijelaskan pada bab 1, langkah pertama adalah mengumpulkan data tweet dari twitter yang akan digunakan sebagai data train dan data test.

Setelah data terkumpul, proses selanjutnya adalah text preprocessing pada setiap tweet meliputi proses case fold, tokenizing, filtering. Selanjutnya tweet dibuat menjadi sebuah Vector Space Model dengan pendekatan bag of word dan setiap kata pada bag of word akan di beri bobot dengan metode TF-IDF.

Setelah melewati tahap pembobotan kata, kemudian dilakukan teknik klasifikasi dengan menggunakan Support Vector Machine. Hasil dari klasifikasi tersebut lalu 
dievaluasi terlebih dahulu. Tahap terakhir penelitian penulis akan menarik kesimpulan berdasarkan evaluasi hasil dari klasifikasi pada tahap sebelumnya.

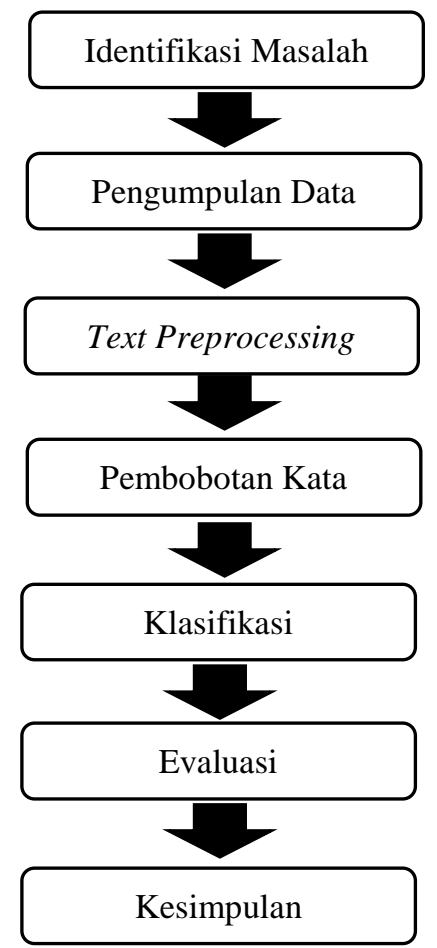

Gambar 2.1. Prosedur Penelitian

\section{Metodologi Penelitian}

\subsection{Tempat dan Waktu Penelitian}

Penelitian ini dilakukan di Program Studi Pendidikan Teknik Informatika dan Komputer Fakultas Teknik Universitas Negeri Jakarta. Penelitian ini dilaksanakan sejak bulan Oktober 2016 hingga Januari 2017.

\subsection{Alat dan Bahan Penelitian}

Hardware

1. Processor AMD E2-1800, $1.7 \mathrm{GHz}$

2. Memory RAM 4 GB DDR 3

3. Harddisk $500 \mathrm{~GB}$

Software

1. Sistem Operasi Windows 7 Ultimate 64-bit Operating System

2. Microsoft Excel 2016 64-bit

3. Notepad

4. Anaconda 3 64-bit

5. PyCharm Community Edition 2016.2.3

6. Menggunakan modul dan fungsi yang ada pada www.scikitlearn.org.

\subsection{Diagram alir penelitian}

Langkah-langkah pada penelitian ini dapat dilihat pada gambar 3.1.

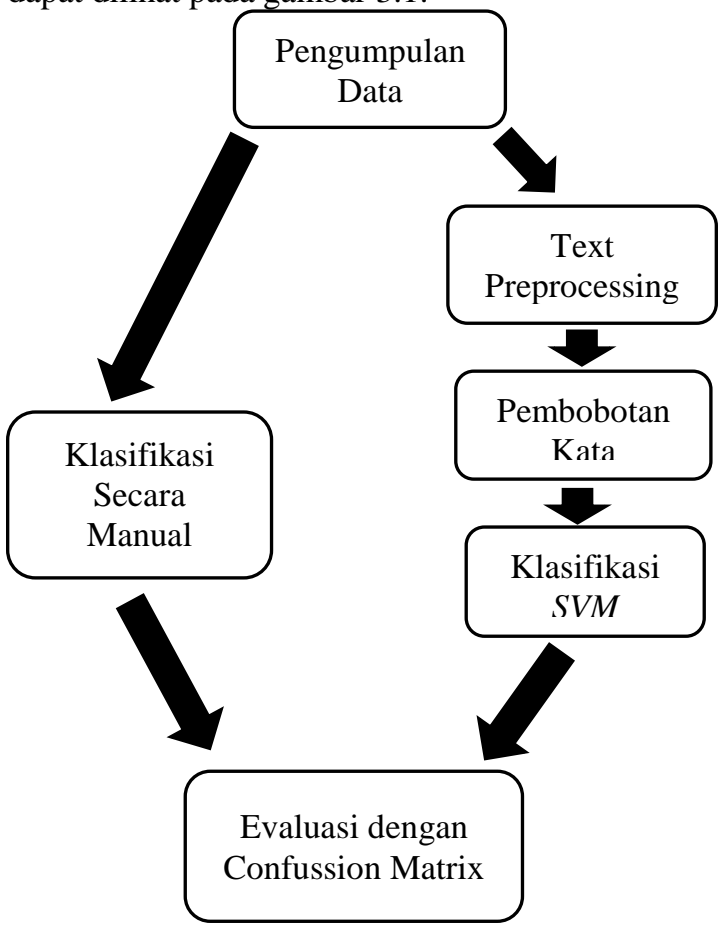

Gambar 3.1 Diagram Alir Penelitian

\subsection{Teknik dan Prosedur Pengumpulan data}

Data yang dibutuhkan adalah tweettweet yang diambil dari website Twitter berbahasa Indonesia. Data yang diambil berupa tweet sebanyak 400 tweet. Proses pengumpulan data dilakukan secara manual.

\subsubsection{Klasifikasi Secara Manual}

Pada proses 1 dari data yang telah terkumpul akan dilakukan pengklasifikasian untuk menentukan tweet mana yang akurat dan tidak akurat. Maksud dari akurat disini adalah tweet yang mengandung kata "banjir" yang benar memberikan informasi mengenai banjir, bukan tweet yang mengandung kata "banjir" tetapi tidak ada hubungannya dengan peristiwa banjir (penggunaan kata "banjir" sebagai kata khiasan).

\section{Hasil Penelitian}

\subsection{Deskripsi Hasil Penelitian}

Penelitian ini terdiri dari pengumpulan data, melalui tahap case folding, tahap tokenizing, tahap filtering, pembobotan kata lalu mengklasifikasi data dengan algoritma Support Vector Machine. Data sebanyak 400 tweet akan diuji di dalam program implementasi algoritma Support Vector Machine untuk menentukan apakah tweet 
tersebut termasuk "false" atau "true". Yang dimaksud dengan "false" adalah apabila tweet tersebut menggunakan kata "banjir" tetapi tidak berkaitan dengan bencana alam berupa banjir. Sedangkan yang dimaksud dengan "true" adalah apabila tweet tersebut menggunakan kata "banjir" yang berisikan informasi mengenai suatu daerah yang sedang terjadi bencana alam berupa banjir.

\subsection{Analisis Data Penelitian}

Setelah menghitung nilai IDF dan diberi label, selanjutnya masuk ke tahap klasifikasi data. Kumpulan data tweet tersebut akan di klasifikasi menggunakan algoritma Support Vector Machine. Pada pengujian algoritma Support Vector Machine di penelitian ini menggunakan metode $K$-fold Cross Validation. Sehingga pengklasifikasian akan dilakukan sebanyak 10 kali (dengan presentase data test sebanyak $10 \%$ dari data keseluruhan). Dengan menggunakan data test yang berbeda-beda diharapkan hasil dari klasifikasi akan semakin valid.

Instrumen yang digunakan oleh peneliti untuk mengaplikasikan algoritma Support Vector Machine dalam bahasa pemrograman python adalah PyCharm Community Edition 2016.2.3. Dalam pemrosesan klasifikasi, data yang digunakan adalah hasil dari VSM yang mengitung nilai IDF lalu akan diklasifikasi menggunakan algoritma Support Vector Machine.

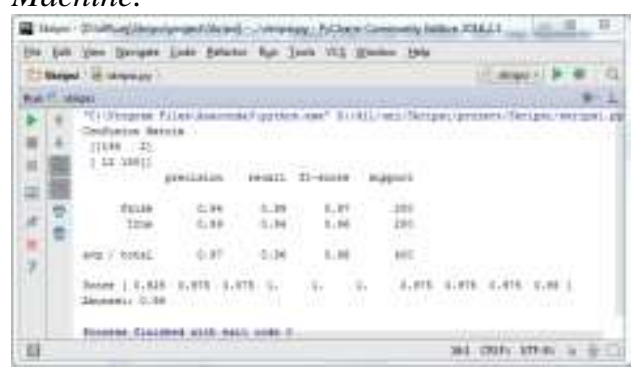

Gambar 4.5. Hasil Klasifikasi Algoritma Support Vector Machine

Pada gambar 4.5 adalah hasil akhir dari klasifikasi menggunakan algoritma Support Vector Machine. Berikut adalah detail hasil klasifikasi dengan menggunakan Confusion Matrix:

Tabel 4.3 Tabel Confusion Matrix

\begin{tabular}{|l|l|l|l|}
\hline \multicolumn{2}{|c|}{} & \multicolumn{2}{l|}{$\begin{array}{l}\text { Diklasifikasikan } \\
\text { sebagai }\end{array}$} \\
\cline { 3 - 4 } \multicolumn{2}{|c|}{} & False & True \\
\hline \multirow{2}{*}{$\begin{array}{l}\text { Klasifikasi } \\
\text { yang benar }\end{array}$} & False & 198 & 2 \\
\cline { 2 - 4 } & True & 12 & 188 \\
\hline
\end{tabular}

Pada kelas false algoritma Support Vector Machine berhasil mengklasifikasikan sebanyak 210 tweet. Namun yang sesuai dengan kelas false hanya sebanyak 198 tweet dan 12 tweet lainnya algoritma salah dalam mengklasifikasinya. Dan 12 tweet seharusnya kelas true dianggap kelas false oleh algoritma Support Vector Machine. Pada kelas true algoritma Support Vector Machine mengklasifikasi sebanyak 190 tweet. Dengan kelas yang sesuai sebanyak 188 tweet dan 2 lainnya salah dalam pengklasifikasiannya. Berikut adalah hasil Precision, Recall dan Akurasi tabel Confusion Matrix:

Tabel 4.4 Tabel Hasil Precision, Recall

\begin{tabular}{|l|l|l|}
\hline Kelas & Precision & Recall \\
\hline False & 0.94 & 0.99 \\
\hline True & 0.99 & 0.94 \\
\hline avg & 0.97 & 0.96 \\
\hline
\end{tabular}

Berdasarkan tabel 4.4 pada kelas false memiliki nilai precision sebesar 0.94 dan nilai recall 0.99 . dan pada kelas true memiliki nilai precision sebesar 0.99 dan nilai recall 0.94 .

Tabel 4.5 Tabel Hasil Akurasi

\begin{tabular}{|c|c|}
\hline $\begin{array}{c}\text { Cross } \\
\text { Validation }\end{array}$ & Akurasi \\
\hline 1 & 0.925 \\
\hline 2 & 0.975 \\
\hline 3 & 0.875 \\
\hline 4 & 1 \\
\hline 5 & 1 \\
\hline 6 & 1 \\
\hline 7 & 0.975 \\
\hline 8 & 0.975 \\
\hline 9 & 0.975 \\
\hline 10 & 0.95 \\
\hline $\begin{array}{c}\text { Akurasi } \\
\text { Akhir }\end{array}$ & 0.96 \\
\hline
\end{tabular}

Berdasarkan hasil akurasi dari seluruh Cross Validation mendapatkan nilai rata-rata sebesar 0.96 .

\section{Kesimpulan dan Saran}

\subsection{Kesimpulan}

Berdasarkan hasil penelitian ini dengan judul "Kinerja Algoritma Support Vector Machine dalam Menentukan Informasi Banjir di Twitter" dapat disimpulkan bahwa hasil klasifikasi dari kinerja algoritma Support Vector Machine dalam menentukan tweet mengenai banjir dianggap bagus karena memiliki nilai precision sebesar 0.97 , recall sebesar 0.96 dan akurasi 0.96 . 


\subsection{Saran}

Peneliti memiliki saran untuk penelitian lainnya yang akan dilakukan terkait dengan penggunaan algoritma Support Vector Machine dalam mengklasifikasi teks, yaitu :

1. Menggunakan metode K-Fold Cross Validation sehingga hasil klasifikasi menjadi semakin valid.

2. Memperbanyak jumlah data, sehingga algoritma dapat mempelajari berbagai macam karakteristik jenis data. Dan semakin akurat juga hasilnya.

3. Menambahkan satu atau beberapa algoritma sebagai pembanding hasil akurasi, sehingga menemukan algoritma yang terbaik.

\section{Daftar Pustaka}

[1] Dika Putri Utama, A., \& Permana, P. Penggunaan Twitter sebagai Media Pembelajaran untuk Meningkatkan Kemampuan Menulis Kalimat Sederhana dalam Pembelajaran Bahasa Jerman.

[2] Dina, M. (2015). Skripsi Penerapan Data Mining untuk Rekomendasi Beasiswa Pada SMA Muhammadiyah Gubug Menggunakan Algoritma C4. 5., Jurusan Teknik Informatika, Fakultas Ilmu Komputer, UNIDUS, Semarang.

[3] Prilianti, K. R., \& Wijaya, H. (2014). Aplikasi Text Mining untuk Automasi Penentuan Tren Topik Skripsi dengan Metode K-Means Clustering. Jurnal Cybermatika, 2(1).

[4] Widiastuti, D. (2007). Analisa Perbandingan Algoritma SVM, Naive Bayes, dan Decision Tree dalam Mengklasifikasikan Serangan (Attacks) pada Sistem Pendeteksi Intrusi. Jur. Sist. Inf. Univ. Gunadarma, 1-8.

[5] Zakapedia, 2015. Pengertian Banjir, Penyebab, Dampak, Cara Menanggulangi. http://www.artikelsiana.com/2015/08/p engertian-banjir-penyebab-dampakcara.html (diakses pada tanggal 4/1/17) 